\title{
Fin des empires et naissance d'un État : le rêve ukrainien de Guillaume de Habsbourg
}

Das Ende von Kaiserreichen und die Geburt eines Staates: der ukrainische Traum des Wilhelm von Habsburg

The End of Empires and the Birth of a State: The Ukrainian Dream of Wilhelm von Habsburg

\section{Iryna Dmytrychyn}

\section{CpenEdition}

\section{Journals}

Édition électronique

URL : http://journals.openedition.org/austriaca/413

DOI : 10.4000/austriaca.413

ISSN : 2729-0603

\section{Éditeur}

Presses universitaires de Rouen et du Havre

Édition imprimée

Date de publication : 1 décembre 2018

Pagination : 195-206

ISBN : 979-10-240-1354-1

ISSN : 0396-4590

\section{Référence électronique}

Iryna Dmytrychyn, «Fin des empires et naissance d'un État : le rêve ukrainien de Guillaume de Habsbourg », Austriaca [En ligne], 87 | 2018, mis en ligne le 01 mars 2020, consulté le 29 janvier 2021. URL : http://journals.openedition.org/austriaca/413; DOI : https://doi.org/10.4000/austriaca. 413 


\section{Fin des empires et naissance d'un État : le rêve ukrainien de Guillaume de Habsbourg}

L'apparition de plusieurs États nationaux après l'effondrement de l'Empire austro-hongrois ne faisait de doute pour personne. Les questions qui demeuraient ouvertes à ce stade étaient de savoir quel serait leur nombre et comment concilier les attentes et les aspirations des uns et des autres. L'Ukraine indépendante était une potentialité, bien qu'elle ne figurât pas dans les 14 points énoncés par le président américain Wilson le 8 janvier 1918. La question ukrainienne avait pourtant été soulevée dès le début de la guerre ${ }^{1}$ et, au sein même de la dynastie habsbourgeoise, elle avait un promoteur : le neveu de l'empereur François-Joseph, Guillaume de Habsbourg-Lorraine (1895-1948), qui

1. Voir à ce sujet : Serhij Popyk, Українці в Австрії 1914-1918. Австрійська політика в українському питанні періоду великої війни (Les Ukrainiens en Autriche 1914-1918. La politique autrichienne dans la question ukrainienne pendant la Grande Guerre), Kyiv-Tchernivtsi, Zoloti lytavry, 1999 ; Volodymyr Trofymovytch, « Український i польський чинники в політиці Австро-Угорщини у 1914 році » (Les facteurs ukrainien et polonais dans la politique de l'Autriche-Hongrie en 1914), Наукові записки Національного Університету “Острозька Академія" (Cahiers de l'Académie d'Ostrog), 2015, $\mathrm{n}^{\circ} 24$. Voir, au sujet de l'entité militaire ukrainienne créée au sein de l'armée impériale, les « Tirailleurs de la Sitch » (Ukrainische Sitschower Schützen) : Mykola Lytvyn, "Легіон українських січових стрільців : військове навчання, виховання, бойовий шлях » (La légion ukrainienne des Tirailleurs de la Sitch : entraînement militaire, éducation, parcours combattant) dans Oleksandr Rejent (dir.), Велика війна 1914-1918 рр. і Україна (La Grande Guerre et l'Ukraine dans les années 19141918), Kyiv, Natsionalna Akademija Nauk, Instytout Istoriji Ukrajiny, 2 vol., vol. 1 : Iсторичні нариси (Esquisse historique), 2014, p. 159-179 (éd. française en cours). À noter que la question ukrainienne était aussi bien autrichienne (Galicie et Bucovine) que hongroise (Ruthénie transcarpatique) et qu'elle comprenait la dimension russe («moscophile ») - réelle ou supposée - des Ukrainiens d'Autriche-Hongrie, exploitée et instrumentalisée par le tsar. 
d'après son propre témoignage avait découvert les Ukrainiens à l'âge de 17 ans, intrigué par les images de bandits sauvages qu'on en faisait dans le domaine polonais de son père ${ }^{2}$, avant de prendre leur parti, peut-être par défi ${ }^{3}$.

Il forge sa légende ukrainienne auprès des soldats dès juin 1915, lorsqu'engagé dans l'armée au sein d'une unité à prédominance ukrainienne, il se fait appeler Vasyl, vêtu d'une chemise brodée ukrainienne ${ }^{4}$, puis lorsqu'il se retrouve en Ukraine et prend en avril 1918 le commandement des "Tirailleurs de la Sitch ${ }^{5}$ ", mais aussi à Vienne lorsqu'il se lance dans les batailles politiques ou ayant valeur de symbole, comme le changement de dénomination ethnique de Ruthènes en Ukrainiens ${ }^{6}$.

Vue de Vienne, la question ukrainienne butait sur un autre projet, polonais, qui avait lui aussi ses promoteurs, dont le propre père de Guillaume, l'archiduc Charles-Étienne de Teschen (Erzherzog Karl Stephan von Österreich, 1860-1933). Les deux projets, polonais et ukrainien, concernaient les mêmes territoires et il était difficile, voire impossible, de s'en sortir en gardant équilibre et équité, tant sur le plan interne qu'externe, car les deux projets étaient aussi transfrontaliers. Alors qu'on songeait à un royaume de Pologne élargi aux terres polonaises prises sur la Russie au sein de la Monarchie habsbourgeoise, proclamé effectivement en novembre 1916, Guillaume, de plus en plus sollicité et aguerri politiquement, poussait le projet de création d'une entité dynas-

2. Мемуари Вільгельма Габсбурга Полковника УСС (Mémoires de Guillaume de Habsbourg, colonel dess tirailleurs de la Sitch), 28 septembre 1919. Voir Yuriy Terechtchenko et Tetiana Ostachko, Український патріот династії Габсбургів (Un patriote ukrainien de la dynastie des Habsbourg), Kyiv, Tempora, 2008, p. 110.

3. Cette thèse est développée par son récent biographe : Timothy Snyder, Le prince rouge. Les vies secrètes d'un archiduc de Habsbourg [2008], Olivier Salvatori (trad.), Paris, Gallimard, 2013, p. 12-16.

4. Ibid., p. 100-101. Voir également ses Mémoires : Мемуари Вільгельма Габсбурга, ор. сit., p. 114-115.

5. Ibid., p. 119-120. Il explique l'attachement que lui portaient les tirailleurs de la manière suivante : «Ils m'ont bien reçu, car ils savaient que je n'avais nulle intention de conduire une politique autrichienne, mais uniquement nationale. »

6. La question du changement de nom qui agitait les cercles gouvernementaux et scientifiques de l'Empire revient souvent dans sa correspondance avec les responsables ukrainiens : il plaidait pour que la désignation de l'Ukraine soit attribuée à la Galicie orientale, dont les habitants deviendraient des Ukrainiens et non des Ruthènes, en signe d'unité des Ukrainiens des deux empires, russe et austro-hongrois. Voir Guillaume de Habsbourg à K. Houjkovsky, Baden, 25 janvier 1917 (Yuriy Terechtchenko et Tetiana Ostachko, Український nampiom, ор. cit., p. 156) ; Guillaume de Habsbourg à K. Houjkovsky, Baden, $1^{\text {er février }} 1917$ (ibid., p. 136). Voir à ce sujet : Serhij Popyk, Українці в Aвcmpiï, op. cit., chap. 3. 
tique ukrainienne au sein de l'Empire ${ }^{7}$. Celui-ci visait à séparer la Galicie occidentale, qui serait dévolue à la Pologne, de la Galicie orientale, laquelle, réunie à la Bucovine, formerait un ensemble à forte population ukrainienne : une principauté d'Ukraine ${ }^{8}$. Reçu en février 1917 en audience par le nouvel empereur pour lui présenter cette configuration, Guillaume croyait la partie gagnée?.

Alors que sur fond d'effondrement de la Russie émergeait un État ukrainien à Kiev (Kyiv), avec l'instauration en mars 1917 du Conseil central (Centralna Rada) (qui se contentait à cette époque de l'autonomie au sein du nouvel État russe), les parlementaires ukrainiens à Vienne ont demandé en mai la création d'une entité ukrainienne habsbourgeoise, tout en proclamant leur soutien à la Rada. Peu de temps après, en juillet-août 1917, l'empereur Charles entreprit un voyage en Galicie orientale, en compagnie de Guillaume, en raison, lui aurait-il confié, de ses " très bonnes connaissances des circonstances actuelles ", et afin que " les Ukrainiens aient un signe public de [son] intérêt pour ce pays et ce peuple ${ }^{10}$ ». C'est aussi Charles qui avait présenté Guillaume à $\mathrm{M}^{\text {gr }}$ Andreï Scheptyckyj, le métropolite de l'Église grecque-catholique ukrainienne, qui revenait de son exil russe : à l'occasion de cette rencontre, Guillaume aurait reçu un nom ukrainien en plus du prénom qu'il s'était lui-même choisi. Désormais, il serait Vasyl Vychyvanyi, soit « Basile le Brodén ${ }^{11}$ ».

Après la prise de pouvoir par les bolcheviques à Petrograd en octobre 1917, le Conseil central proclame à Kyiv le 22 janvier par son Quatrième Universal l'indépendance de l'Ukraine. Exsangue, elle essaye de conclure une paix séparée avec les Puissances centrales, à Brest-Litovsk. Guillaume aurait été de ceux qui auraient suggéré de jouer la carte de la puissance

7. Voir ses échanges avec les personnalités ukrainiennes et notamment sa réaction à la proclamation du royaume de Pologne : Guillaume de Habsbourg à K. Houjkovsky, 7 novembre 1916 (Yuriy Terechtchenko et Tetiana Ostachko, Український nатріот, op. cit., p. 138).

8. Timothy Snyder, Le prince rouge, op. cit., p. 106-107. Voir, pour un bon exposé des visions ukrainiennes, formulées dès le début de la guerre, où l'argument principal est la nécessité d'une partition de la Galicie en deux entités : Mykhajlo Lozynskyj, Утворення українського коронного краю в Австрії (La création de la principauté d'Ukraine en Autriche), s. l., Bibliothèque politique, 1915.

9. Timothy Snyder, Le prince rouge, op. cit., p. 108. Voir également, au sujet de ses discussions avec Charles : Мемуари Вільгельма Габсбурга, ор. сіt., p. 117-118.

10. Guillaume de Habsbourg à Mykola Vasylko, $1^{\text {er }}$ août 1917 (Yuriy Terechtchenko et Tetiana Ostachko, Український nampiom, ор. cit., p. 196).

11. Timothy Snyder, Le prince rouge, op. cit., p. 112-113. Voir également le témoignage sur l'activisme de Guillaume dans ce cadre : Nykyfor Hirniak, Полк. Василь Вишиваниц (Le colonel Vasyl Vychyvanyi), Winnipeg, D. Mykytuk, 1956, p. 11. 
agricole, atout essentiel dans la situation de Vienne et de Berlin, confrontés tous deux à d'importantes pénuries alimentaires ${ }^{12}$. Le 27 janvier, l'Ukraine signe avec l'Allemagne, l'Autriche, l'Empire ottoman et le royaume de Bulgarie, la "paix du pain " (dénommée ainsi en raison des livraisons de vivres consenties par la partie ukrainienne). Outre le premier document international reconnaissant l'existence d'un État ukrainien, l'Ukraine a aussi obtenu des Habsbourg et des Allemands le transfert de la région de Chełm/Kholm et de la Podlachie et, par un protocole secret signé dans la nuit du 8 au 9 février 1918, la création d'un pays de la couronne (Kronland), composée de la Galicie orientale et de la Bucovine, qui devait voir le jour avant le $1^{\text {er }}$ juillet 1918. Guillaume en était transporté de joie : "Croyezmoi, que ce jour du 9 février est pour moi en tant qu'Ukrainien, car je me sens Ukrainien, un des plus beaux jours de ma vie [...] Je suis certain qu'un avenir merveilleux attend les Ukrainiens de Galicie ${ }^{13}$. ”

En février 1918, Guillaume de Habsbourg est placé à la tête du groupe de combat "Archiduc Guillaume » et envoyé en Ukraine, où il prend aussi la direction des Tirailleurs de la Sitch. Se retrouvant dans les terres mythiques des Cosaques zaporogues, à la tête de plusieurs milliers de soldats et officiers ukrainiens et au contact des villageois et des citadins de l'Ukraine des steppes, Vasyl Vychyvanyi se dévoue au service de sa patrie d'élection, sans oublier la fidélité qu'il doit à son pays d'origine et à sa dynastie. Il essaye de protéger les villageois, alors que les réquisitions de produits alimentaires sont de plus en plus difficiles à réaliser. Mais surtout, il « ukrainise » en s'efforçant de "susciter une conscience nationale parmi la paysannerie ${ }^{14} »$ en donnant l'exemple de ses troupes et payant de sa personne ${ }^{15}$. Les souvenirs qu'il laisse à tous ceux qui l'approchent ne font qu'entretenir sa légende ${ }^{16}$. Au point de faire naitre des inquiétudes chez les Allemands et l'hetman Pavlo Skoropadsky qui le soupçonnaient, lui et l'Autriche, de poursuivre leurs propres objectifs : ils œuvrèrent donc

12. Timothy Snyder, Le prince rouge, op. cit., p. 115-116. Voir aussi : Nykyfor Hirniak, Полк. Василь Вишиваний, ор. сіt., p. 13.

13. Guillaume de Habsbourg au métropolite Andreï Scheptyckyj, 14 février 1918 (Yuriy Terechtchenko et Tetiana Ostachko, Український nampiom, ор. cit., p. 230). Voir d'autres lettres de cette époque dans le même volume.

14. Timothy Snyder, Le prince rouge, op. cit., p. 13 et 124-129.

15. Mykola Lytvyn, « Легіон українських січових стрільців... », art. cité, p. 176.

16. Voir par exemple l'histoire de la rencontre manquée avec l'anarchiste Nestor Makhno : Nykyfor Hirniak, Полк. Василь Вишиваний, ор. cit., p. 32-34. Ou bien l'histoire des paysans révoltés qui souhaitaient avoir pour hetman « le grand prince Guillaume »: Dilo, Lviv, 8-10 mai 1931 (Yuriy Terechtchenko et Tetiana Ostachko, Украйнський патріom, op. cit., p. 247). 
pour obtenir son départ de la région. Les projets de remplacer l'hetman existaient bel et bien ; Guillaume est tenté, consulte l'empereur, mais ne se lance pas $^{17}$. À la même époque, le protocole secret promettant la création d'une terre ukrainienne au sein de la couronne autrichienne est caduc, les livraisons de blé promises n'arrivant pas ${ }^{18}$.

Lors de la session du Parlement autrichien ouverte le $1^{\text {er }}$ octobre 1918, largement consacrée aux questions de la paix et de la future configuration de l'Empire, le délégué ukrainien Semen Vityk présente le 4 octobre une déclaration :

Le peuple ukrainien, qui compte en Autriche plus de 4 millions et en Ukraine plus de 40 millions de personnes, est situé au milieu des pays slaves et dans le voisinage avec les peuples roumain, turc et hongrois. Pendant des siècles, le peuple ukrainien dut faire l'expérience du joug et de l'oppression [...] Par conséquent, nous demandons le droit à l'autodétermination du peuple ukrainien [...] Le peuple ukrainien aspire comme unique condition de sa vie nationale au sein des États libres d'Europe, à la réunion de toutes les régions ukrainiennes de l'Autriche-Hongrie, la région de Chelm, la Podlachie et la Volhynie en un seul État républicain indépendant de tous les peuples slaves et d'autres pays voisins ${ }^{19}$.

Le 16 octobre 1918, Charles rendit publique sa proposition de réorganisation de l'Empire en une fédération d'entités nationales. Pensant encore pouvoir garder la main, Guillaume demandait aux leaders ukrainiens que le nouvel État ukrainien fût partie intégrante de la Monarchie ${ }^{20}$. Mais il était trop tard et les Ukrainiens voyaient déjà plus loin et surtout observaient avec inquiétude les mouvements des Polonais ${ }^{21}$.

17. Timothy Snyder, Le prince rouge, op. cit., p. 122-135 ; Nykyfor Hirniak, Полк. Василь Вишиваний, ор. cit., p. 22-27. Voir également son propre témoignage sur cette période de sa vie dans les steppes : Мемуари Вільгельма Габсбурга, ор. сit., p. 120-121 ; Автобіограбічні спогади Вільгельма Габсбурга-Лотрінгена, Українські Січові стрільці з весни 1918 р. до перевороту в Австрії (Souvenirs autobiographiques de Guillaume de Habsbourg-Lorraine, Les Tirailleurs de la Sitch du printemps 1918 jusqu'au renversement en Autriche), dans Yuriy Terechtchenko et Tetiana Ostachko, Український патріот, ор. сіt., p. 127-132.

18. Timothy Snyder, Le prince rouge, op. cit., p. 122-135.

19. Cité d'après Oleksandr Roublev, « Західно-українська Народна Республіка » (La République populaire d'Ukraine occidentale), dans Oleksandr Rejent (dir.), Велика війна 1914-1918 рр. і Україна..., ор. сіt., р. 691.

20. Voir sa lettre adressée au métropolite Scheptyckyj, où il expose ses arguments et essaye d'amadouer son interlocuteur par la question religieuse : Guillaume de Habsbourg au métropolite Andreï Scheptyckyj, Tchernivtsi, 18 octobre 1918 (Yuriy Terechtchenko et Tetiana Ostachko, Український nampiom, ор. сit., p. 236-238).

21. Un résumé des griefs ukrainiens à l'égard de la Monarchie se trouve dans la lettre de 
Le 19 octobre 1918, au lendemain de l'appel de Wilson invitant les composantes de l'Autriche-Hongrie à proclamer leur indépendance, une Constituante qui réunit à Lviv près de 500 parlementaires, députés de Galicie et de Bucovine, des représentants des partis politiques, de diverses organisations et du clergé ukrainiens, proclama la création d'un État indépendant sur les terres à majorité ethnique ukrainienne et élut un Conseil national ukrainien (CNU-UNR), nommant à sa tête Yevhen Petrouchevytch. Le 21 octobre, ce dernier a présenté un plan de transmission pacifique du pouvoir légal, d'après lequel les trois délégations du CNU (à Vienne, Lviv/Lemberg et Tchernivtsi/Czernowitz) devaient œuvrer auprès des autorités autrichiennes en ce sens ${ }^{22}$.

Soutenus par les pays de l'Entente et les États-Unis, les responsables polonais qui réclamaient depuis longtemps l'ensemble de la Galicie avaient proclamé la création d'un État indépendant en ce même mois d'octobre 1918. L'arrivée de la commission polonaise à Lwów (Lemberg/Lviv) était prévue le $1^{\text {er }}$ novembre. Le 31 octobre, le Conseil national ukrainien et le Comité militaire central, constatant que Vienne ne se pressait pas pour faire pencher la balance en faveur des demandes ukrainiennes, décidèrent après moult hésitations de prendre les devants. Dans la nuit du $1^{\text {er }}$ novembre, les Ukrainiens prirent le contrôle de la ville de Lemberg et de ses principaux bâtiments : "S'étant couchée le 31 octobre 1918 sous le pouvoir autrichien exercé par les Polonais, la population de Lviv s'est réveillée le $1^{\text {er }}$ novembre sous le pouvoir du Conseil national ukrainien. Un drapeau bleu et jaune, symbole de ce pouvoir, flottait sur l'hôtel de ville ${ }^{23}$."

Le jour même, le général Karl Georg Huyn, gouverneur autrichien qui avait quelques jours auparavant refusé d'accéder aux demandes ukrainiennes, a cédé ses prérogatives à son adjoint, Volodymyr Decykewycz. Ce dernier, se référant au manifeste de l'empereur du 16 octobre et en réponse à la volonté exprimée par le peuple ukrainien, transmit le pouvoir au Conseil national ukrainien. Un document officiel signé par les deux parties, Decykewycz au nom du pouvoir central et trois représen-

Mykola Vasylko adressée à Guillaume en avril 1917, notamment sur le fait que seule la révolution en Russie aurait fait avancer le dossier ukrainien (Yuriy Terechtchenko et Tetiana Ostachko, Український nampiom, ор. cit., p. 204-207).

22. Oleksandr Roublev, « Західно-українська Народна Республіка », art. cité, p. 691.

23. Mykhajlo Lozynsky, Галичина в рр. 1918-1920 (La Galicie dans les années 1918-1920), dans La révolution ukrainienne. Études et documents, Vienne, Institut sociologique ukrainien, 1921-1922, vol. 5, p. 41. Voir également Oleksandr Roublev, « Західно-українська Народна Республіка », art. cité, p. 696. 
tants ukrainiens au nom du CNU fut établi. Guillaume de Habsbourg, tombé malade en Bucovine où il s'était retiré avec ses troupes, faisait le nécessaire pour que les unités des Tirailleurs de la Sitch pussent rejoindre Lviv. Sans prendre aucune part aux événements, il s'était engagé à être « un citoyen fidèle de l'État ukrainien ${ }^{24} »$.

Toujours le $1^{\text {er }}$ novembre, les appels du CNU à tous les habitants de Lemberg ont été placardés dans la ville: "Par la volonté du peuple ukrainien, un État ukrainien a été créé sur les terres ukrainiennes de l'ancienne Monarchie austro-hongroise. " Un autre texte, aux accents bien plus emportés, s'adressait expressément aux Ukrainiens : «Peuple d'Ukraine ! On porte à ta connaissance la nouvelle sacrée de Ta libération de l'esclavage séculaire. Désormais, Tu es maître de ta terre, libre citoyen de l'État ukrainien. » L'appel promettait l'égalité citoyenne sans distinction d'appartenance ethnique ou religieuse ainsi que l'organisation d'élections générales, libres et directes de l'Assemblée constituante pour décider de l'avenir de l'État ukrainien.

Le pouvoir du nouvel État s'est installé dans plusieurs grandes villes : Stanislaviv, Kolomya, Sniatyn, Rava-Ruska, Jovkva, Ternopil, Przemyśl, Boryslav, Sambir, Drohobytch et bien d'autres ${ }^{25}$. L'enthousiasme était général parmi les Ukrainiens, aussi bien de Galicie que de Bucovine, mais il fut de courte durée. Le chef-lieu Tchernivtsi est tombé le 11 novembre, puis toute la Bucovine est passée sous le contrôle roumain avant la fin du mois. Le 11 novembre les Polonais reprennent le contrôle de Przemyśł.

Le gouvernement créé le 9 novembre adoptait le nom officiel de République populaire d'Ukraine occidentale (ZUNR) et jetait les bases de la future constitution : celle-ci confirmait que le nouvel État s'érigeait sur tout l'espace peuplé majoritairement d'Ukrainiens, conformément à la carte ethnographique de Karl Czoernig de 1855. L'introduction du mot " occidentale » se référait clairement à l'État ukrainien - la République populaire d'Ukraine (UNR) - formé sur les ruines de l'empire des Romanov en novembre 1917, d'abord sous forme autonome au sein de la Rus-

24. Yuriy Terechtchenko et Tetiana Ostachko, Український патрiom, op. cit., p. 59. Il n’y avait pas de consensus quant au rôle qu'il devait jouer : d'une part il semblait évident que le projet ukrainien n'avait pas le soutien de Vienne et d'autre part, cherchant les faveurs des vainqueurs, les responsables ukrainiens ne jugeaient pas opportun de mettre en avant un Habsbourg.

25. Voir Oleksandr Roublev, « Західно-українська Народна Республіка », art. cité, p. 698. La superficie initiale dont se réclamait l'UNR était de $70000 \mathrm{~km}^{2}$; elle n'a cessé de se réduire par la suite. 
sie, puis indépendante en janvier 1918. Alors que le pouvoir lui a échappé en avril 1918 au profit de l'hetman Skoropadsky, soutenu par les Allemands et les Autrichiens, l'UNR fait son retour sous forme de Directoire en novembre 1918. C'est avec elle que la République populaire d'Ukraine occidentale (ZUNR) signe le $1^{\text {er }}$ décembre 1918 un acte hautement symbolique de l'unité ukrainienne - Zlouka - dont la proclamation solennelle eut lieu le 22 janvier 1919 sur la place Sainte-Sophie à Kyiv²6.

Peut-être par naïveté, certainement aussi par manque d'expérience, les dirigeants de la ZUNR se sont concentrés sur les attributs institutionnels du nouvel État, et se sont fait surprendre par la volonté des Polonais de construire leur propre État dont la Galicie avec Lwów, ville à moitié polonaise, était indissociable. Mieux équipés, plus expérimentés et non moins soutenus par la ferveur populaire et décidés à construire une Pologne comprenant les parties issues des deux empires, ils sont presque immédiatement passés à l'offensive, réduisant petit à petit l'avantage que les Ukrainiens avaient engrangé par leur action surprise. Le 22 novembre, soit trois semaines après leur coup d'éclat, les forces ukrainiennes évacuèrent Lviv.

Cet échec conduisit à la réorganisation des forces galiciennes et à leur rapprochement avec Kyiv. Désormais liées, les deux parties de l'Ukraine allaient suivre les mêmes combats et en partager les victoires et les défaites. L'unité a été rompue lorsque le Directoire de Petlioura conclut en avril 1920 une alliance avec la Pologne de Piłsudski pour combattre la Russie soviétique, au prix de la cession de la Galicie. Guillaume, on s'en doute, ne l'accepta pas.

La question de la Galicie a été discutée lors de la Conférence de paix de Paris et de la Conférence de Riga censée clore la guerre polono-soviétique, et a été réglée par la Conférence des ambassadeurs en mars 1923 : la Pologne y a obtenu le droit d'incorporer la Galicie à son territoire. Le sort de la Bucovine fut réglé par le traité de Saint-Germain (1919) et celui

26. Relevons que Guillaume était à l'époque contre cette union, estimant que la formation étatique sur les terrains de l'ancien Empire russe n'était pas assez solide et risquait de conduire à la perte l'ensemble, alors que la création d'une entité au sein d'un futur État autrichien avait toutes les chances de se maintenir. Voir Guillaume de Habsbourg au métropolite Andreï Scheptyckyj, Tchernivtsi, 18 octobre 1918 (Yuriy Terechtchenko et Tetiana Ostach, Украӥнський nampiom, op. cit., p. 237). Il est probable qu'en l'occurrence il songeait à son propre projet autrichien, car un an auparavant il plaidait pour la création d'une « Province ukrainienne » qui serait directement dépendante de l'Autriche et dans une certaine mesure autonome, en contrepoids à la partie de l'Ukraine russe libre. Voir Guillaume de Habsbourg à K. Houjkovsky, 9 juin 1916 (ibid., p. 136). Toutefois, l'évocation de Kyiv et de l'Ukraine réunie n'est pas rare dans ses écrits. 
de la Transcarpatie par le traité de Trianon (1920). La réaction soviétique, comme en témoigne la réponse du ministre des Affaires étrangères d'Ukraine, a été d'accuser le grand capital tout en affirmant que l'objectif soviétique n'était pas de récupérer la Galicie, mais d'aider les travailleurs galiciens à combattre les exploiteurs et à provoquer une révolution ${ }^{27}$.

À la lecture de la correspondance de Guillaume publiée récemment (par une équipe exclusivement ukrainienne, ce qui incite à une prudence critique), se dessine la figure d'un homme rêveur, parfois naï et pathétique, mais constant dans son attachement à l'idée ukrainienne, tout au long de son existence et à travers les péripéties de la première moitié du xx ${ }^{e}$ siècle. Alors qu'en 1916 il rêvait d'une Ukraine en paix, avec des gens " heureux et forts ", mais aussi de son propre avenir, où il serait « le premier et le meilleur guide de ce pays ${ }^{28}$ ", en 1917 il clamait que "l'objectif » de sa vie était de "rendre ce peuple heureux » et qu'il y travaillait " jour et nuit ${ }^{29}$ ", et en 1921 il affirmait ne vivre que pour une chose, "voir le Peuple ukrainien libre, indépendant et uni ${ }^{30}$ ». Ses références constantes au peuple et à la justice sociale, notamment dans le domaine agraire, suggèrent que le surnom de « prince rouge » est justifié : sans doute sa façon de concilier des projets à la fois monarchique et démocratique ${ }^{31}$.

Au moins jusqu'à la chute de l'Empire danubien, le projet ukrainien était à ses yeux probablement avant tout autrichien, au service de la couronne et assurément de sa propre personne ${ }^{32}$. Il est vrai qu'il lui est parfois difficile de trancher :

27. Анексія Східної Галичини й У. С. С .Р. Промова Х. Г. Раковського на II-й сесії Всеукраїнського центрального виконавчого комітету vіI-го збору. Відповідь і пояснення Уряду на запит депутата Т. Луценка (Annexion de la Galicie orientale et la R.S.S. d'Ukraine. Discours de Kh. G. Rakovsky lors de la II e session du Comité exécutif central panukrainien de la vil ${ }^{e}$ convocation. Réponse et explications du Gouvernement à la question du député T. Loutsenko), s. l., [éd. d'État d'Ukraine], 1923.

28. Guillaume de Habsbourg à K. Houjkovsky, de l'armée, 15 octobre 1916 (Yuriy Terechtchenko et Tetiana Ostach, Український nampiom, op. cit., p. 136).

29. Guillaume de Habsbourg au même, 9 juin 1916 (ibid., p. 177).

30. Guillaume de Habsbourg à Mykola Vasylko, Rabenstein, 3 mars 1921 (ibid., p. 203).

31. Dans une interview à la presse ukrainienne, il a déclaré : «Elle sera paysanne avec la réforme agraire, ou bien elle disparaitra. Elle disparaitra pour un bref moment, car personne ne pourrait plus étouffer l'esprit qui s'est éveillé », Dilo, Lviv, 8-10 mai 1931. Cité d'après Yuriy Terechtchenko et Tetiana Ostach, Український nampiom, op. cit., p. 249.

32. "Croyez-moi, cher ami, pendant la guerre je me suis habitué aux Ukrainiens et j'ai découvert à quel point ce peuple est courageux et fidèle à l'empereur. Il nous aidera à créer une Grande Autriche forte et puissante » (Guillaume de Habsbourg à K. Houjkovsky, de l'armée, 29 octobre 1916, dans Yuriy Terechtchenko et Tetiana Ostach, Український 
[...] actuellement parmi les hommes très influents est née une nouvelle et à mon avis très bonne idée, qu'on a l'intention de faire appliquer dans peu de temps, à savoir : l'État fédéral autrichien, qui comprendrait "l'Autriche ", « la Hongrie », « la Tchéquie » (Bohême), « la Pologne » en tant que royaumes séparés, auxquels s'ajouteront la fédération des Slaves unis du Sud et la Grande principauté d'Ukraine. Chaque royaume aurait alors son souverain. Le roi de Hongrie, de Bohême... Pour l'Ukr[aine], les Slaves du Sud, etc. Et dans chacun de ces États de la fédération, un des archiducs jouera le rôle de régent -c'est une des meilleures idées pour la création de la Grande Autriche unie! Puisse Dieu permettre que la paix qui semble réellement proche, nous apporte la réalisation de nos plans tant attendus, en tout cas nous devons y travailler avec application, pour créer une Autriche nouvelle et forte avec à sa tête un jeune monarque et une grande et forte Ukraine avec la ville de Kyiv comme capitale ${ }^{33}$ !

Et quand il songe à une Ukraine séparée de la Russie, alliée à l'Autriche, est-ce un Habsbourg ou un Ukrainien qui se projette ${ }^{34}$ ? De même, quand il espère que «bientôt apparaîtra une Ukraine totalement libre avec une orientation austrophile ${ }^{35}$ "? Quelle qu'ait pu être la configuration, soit la principauté de Galicie-Bucovine, soit l'Ukraine unie issue des deux empires, il s'agissait certainement d'un projet " commun ", au sein duquel les deux destins et les deux identités, l'une par naissance et l'autre d'élection, devaient coexister sans conflit. Lorsque l'empire d'Autriche disparaît, le choix ukrainien n'est pas renié.

En rédigeant en 1919 quelques pages autobiographiques, il se présente comme « ancien archiduc autrichien, actuellement colonel des $\mathrm{USS}^{36}$ ». À Paris, il vit rue des Acacias, non loin de l'Arc de Triomphe, sous le nom de Vychyvanyi. Le nom de Habsbourg n'était sans doute

nampiom, op. cit., p. 137). Sur ce dernier point, il y a peu d'indications franches et directes dans les échanges avec ses correspondants ukrainiens, même à l'époque des projets de création de la principauté de Galicie-Bucovine.

33. Guillaume de Habsbourg à K. Houjkovsky, Baden, 29 décembre 1916 (Yuriy Terechtchenko et Tetiana Ostach, Украӥнський nampiom, op. cit., p. 146).

34. «Est-ce impossible que l'Ukraine se sépare de la Russie en tant qu'État indépendant et dans le cas où elle devienne autonome et qu'unie à l'Autriche elle devienne un mur-frontière contre la puissante Russie ?» (Guillaume de Habsbourg à Mykola Vasylko, 18 avril 1917 , ibid., p. 203).

35. Guillaume de Habsbourg au même, 30 avril 1917 (ibid., p. 191). C'est Guillaume qui souligne.

36. Мемуари Вільгельма Габсбурга, ор. cit., p. 109. Il en sera de même des années plus tard, lors de l'échange avec un ancien compagnon d'armes : "Je n'ai pas changé, cher ami, mes idées sont toujours les mêmes. Je n'ai pas oublié les Ukrainiens et la question ukrai- 
pas facile à porter, mais il aurait pu se choisir un nom plus conventionnel. En 1921 à Vienne, il publie un recueil de ses poèmes en ukrainien, Les jours passent (Минають дні), dédié aux combattants tombés pour la liberté de l'Ukraine, où les évocations élégiaques de la nature et des paysages des Carpates se mêlent à des appels à ne pas cesser le combat pour la résurrection de l'Ukraine ${ }^{37}$. De fait, entre les deux guerres, à Paris comme à Vienne, il entretient des liens avec différentes personnalités ou organisations ukrainiennes qui échafaudent des projets de retour, ce qui n'échappe pas à la surveillance des services français, entre autres. Épisodique et superficielle, cette activité s'est néanmoins poursuivie pendant et après la guerre.

Enlevé dans la zone britannique à Vienne par les services soviétiques en juin 1947, Guillaume de Habsbourg-Lorraine, alias Vasyl Vychyvanyi, qui s'exprimait avec ses geôliers en ukrainien, est condamné le 22 mai 1948 à vingt-cinq ans de travaux forcés pour son appartenance au renseignement français et ses liens avec les nationalistes ukrainiens ${ }^{38}$. Il est réhabilité le 22 décembre 1989 par le parquet militaire de la région militaire de Kyiv, en l'absence de "preuve [...] confirmant son activité hostile à l'encontre de l'URSS » et en tant que personne qui relève de l'arrêté du Présidium du Conseil suprême de l'URSS du 16 janvier 1989 « sur les mesures complémentaires visant à rétablir la justice à l'égard des victimes des répressions qui ont eu lieu pendant la période des années 1930-1940 et le début des années $1950^{39}$ ». Selon l'acte officiel, Guillaume de Habsbourg meurt à l'hôpital de la prison, le 18 août 1948, à Kyiv. On ignore les circonstances et le lieu de son inhumation, probablement dans la capitale ukrainienne, qu'en 1916

nienne, même si je ne disais rien » (lettre du 27 juin 1941, dans Nykyfor Hirniak, Полк. Василь Вищиваний, ор. сit., p. 42). L'inverse est également vrai : ce sont ses compagnons d'armes qui feront dans les années 1950 les démarches auprès de la Croix-Rouge et des autorités autrichiennes pour connaître son sort. La publication de Nykyfor Hirniak, en hommage posthume, reproduit les réponses obtenues. USS est l'abréviation ukrainienne des Tirailleurs de la Sitch (Українські Січові Стрільиі).

37. Une vingtaine de ces poèmes est reprise dans Yuriy Terechtchenko et Tetiana Ostachko, Український патріот, ор. сit., p. 286-300.

38. Timothy Snyder affirme que son activité antisoviétique avait des raisons ukrainiennes : "Guillaume avait pris de grands risques en espionnant l'Union soviétique dans l'espoir que les puissances occidentales protégeraient l'Ukraine» (Le prince rouge, op. cit., p. 14).

39. Voir les procès-verbaux des auditions (où il est longuement interrogé sur ses activités depuis la première guerre), l'acte d'accusation (qui ne manque pas de les énumérer toutes, y compris ses prétentions monarchiques), l'acte médical de décès et l'acte de réhabilitation, dans Yuriy Terechtchenko et Tetiana Ostachko, Український nampiom, op. cit., p. 250-285. 
il espérait rejoindre en libérateur depuis les tranchées ${ }^{40}$. Ce fut son premier et unique rendez-vous avec la ville.

De nos jours, les nombreuses publications qui lui sont consacrées, entre celle plutôt académique des historiens Yuriy Terechtchenko et Tetiana Ostachko (Un patriote ukrainien de la dynastie des Habsbourg, Kyiv, 2008) et le roman de Natalka Sniadanko (Les Notes soigneuses de l'archiduc Guillaume, Lviv, 2017) ${ }^{41}$, où l'auteur refuse de le faire mourir dans une geôle soviétique et lui invente une vie heureuse avec femme et enfant, ne témoignent que d'une chose : Guillaume de Habsbourg est devenu Vasyl Vychyvanyi, un Ukrainien d'adoption. Même Le prince rouge de Timothy Snyder au titre prêtant à plusieurs interprétations dans un pays post-soviétique, est "sauvé " par la quatrième de couverture de l'édition ukrainienne, parue en 2011, fort différente de l'édition française, qui pose sans ambages la question : "Quel aurait été le destin de notre État si son rêve s'était réalisé ${ }^{42}$ ? "

Réel ou imaginaire, il est présent dans le discours historiographique et public en Ukraine, qui est flattée de compter parmi ses alliés le rejeton d'une grande dynastie, témoin de sa vocation européenne. Le rêve ukrainien revêt dès lors un double sens, celui de Guillaume Vasyl et celui d'une Ukraine ancrée dans l'Europe ${ }^{43}$.

40. «[...] je pense qu'il n'est pas exclu qu'au début de l'année prochaine nous libérions la Galicie orientale et que nous allions plus loin, au fond des régions ukrainiennes - puissions-nous avec l'aide de Dieu atteindre Kyiv, alors la liberté et le bonheur seront avec nous ! » (Guillaume de Habsbourg à K. Houjkovsky, de l'armée, 5 décembre 1916, dans Yuriy Terechtchenko et Tetiana Ostachko, Український naтpiom, op. cit., p. 143).

41. Natalka Sniadanko, Охайні прописи еригериога Вільгельма (Les notes soigneuses de l'archiduc Guillaume), Lviv, Vydavnyctvo Staroho Leva, 2017.

42. Timothy Snyder, Червоний князь. Таємні життя габсбургського еригериола (Le prince rouge. Les vies secrètes d'un archiduc Habsbourg), Kyiv, Grani-T, 2011.

43. C'est dans ce sens que s'expriment en Ukraine deux autres Habsbourg, Karl de Habsbourg-Lorraine et, quelques années plus tôt, son père, Otto de Habsbourg-Lorraine : "Карл фон Габсбург: Європейський Союз немає майбутнього без України » (Karl de Habsbourg : l'Union européenne n'a pas d'avenir sans l'Ukraine), Ecnpecco. TB, 19 février 2017, https://espreso.tv/article/2017/02/19/gabsburg (consulté le 13 avril $2019)$; « Габсбурги считают Европу без Украины “неполной” " (Les Habsbourg considèrent l'Europe comme "incomplète » sans l'Ukraine), https://www.obozrevatel. com/kiyany/news/2017/6/15/32572.htm (consulté le 13 avril 2019). 